\title{
Turizm İşletmelerinde Rasyo Yöntemi ile Finansal Performans Analizi: Konaklama İşletmeleri Üzerine Bir Değerlendirme
}

Dursun $\operatorname{KELEŞ}{ }^{(*)}$

Öz: Turizm sektörü, birden fazla alt sektörde hizmet veren işletmelerden oluşan bir sektördür. Bu sektörde faaliyet gösteren yiyecek-içecek, seyahat ve ulaştırma, tur organizasyonu ve eğlence gibi işletmelerin yanı sıra konaklama işletmeleri de faaliyet göstermektedir. Konaklama işletmelerinin, turizm sektörüne en büyük katkl sağlayan işletmeler olduğunu ifade etmek mümkündür. Konaklama işletmeleri, müşterilerine konaklama hizmeti sunmanın yanında, genellikle yiyecek-içecek, spor, kültür ve eğlence hizmetlerini de bir arada sunan hizmet işletmeleridir.

Konaklama işletmelerinde faaliyetlerin iyi bir şekilde yönetilebilmesi ve işletmelerin sürekliliğinin sağlanabilmesi için konaklama hizmetlerinin finansal durum ve faaliyet sonuçlarının analiz edilerek değerlendirilmesi büyük önem arz etmektedir. Bu noktada, rasyo yöntemiyle analiz konaklama işletmelerinin finansal performansının ölçümünde önemli bir araç olarak değerlendirilebilmektedir. Bu çalışmanın amacı, konaklama işletmelerinde finansal performansın rasyo yöntemiyle analiz edilmesidir. Bu amaçla, Türkiye Cumhuriyet Merkez Bankası resmi internet sitesinde yayımlanan sektör bilançoları temin edilerek rasyo yöntemiyle finansal performans analizi gerçekleştirilmiş ve sonuçları değerlendirilmiştir.

Anahtar Kelimeler: Turizm sektörü, konaklama işletmeleri, oran analizi.

\section{Financial Performance Analysis by Ratio Method in Tourism Enterprises: An Evaluation on Accommodation Enterprises}

Abstract: The tourism sector is a sector that consists of enterprises that serve in more than one sub-sector. In addition to enterprises such as food and beverage enterprises, travel and transportation enterprises, tour organization enterprises, entertainment enterprises operating in this sector, accommodation enterprises also operate. It is possible to state that accommodation enterprises are the enterprises that make the biggest contribution to the tourism sector. Accommodation enterprises are service enterprises that generally offer food and beverage, sports, culture and entertainment services as well as providing accommodation services to their customers.

It is very important to analyze and evaluate the financial status and activity results of accommodation services in order to manage the activities in a good way and to ensure the continuity of the enterprises. At this point, analysis with the ratio method can be considered as an important tool in measuring the financial performance of accommodation enterprises. The aim of this study is to analyze the financial performance of accommodation enterprises by the ratio method. For this purpose, sector balance sheets published on the official website of the Central

${ }^{*}$ Dr. Öğr. Üyesi, Iğdır Üniversitesi Uygulamalı Bilimler Yüksekokulu Gümrük İşletme Bölümü (e-posta: dursun.keles@igdir.edu.tr) (D ORCID ID. https://orcid.org/0000-0001-9075-476X

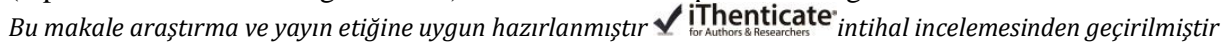


Bank of the Republic of Turkey were obtained and financial performance analysis was carried out using the ratio method and the results were evaluated.

Keywords: Tourism sector, accommodation enterprises, rate analysis.

Makale Geliş Tarihi: 14.06.2021

Makale Kabul Tarihi: 20.12.2021

DOI:10.53487/ataunisosbil.952122

\section{Giriș}

Hizmet sektöründe faaliyet gösteren işletmeler arasında önemli bir yeri olan turizm işletmeleri; diş ticaret hacminin genişletilmesi, istihdam yaratılması ve önemli düzeyde döviz girişinin sağlanması noktasında ülke ekonomileri için önemli katkılar sunmaktadır. Turizm işletmeleri; yiyecek içecek işletmeciliği, seyahat acenteliği ve konaklama işletmeciliği gibi çok geniş bir alanda hizmet vermektedir.

Turizm faaliyetlerinin planlanması, kontrol edilmesi ve sürekliliğinin sağlanması konusunda öngörüde bulunulabilmesi için sektörde önemli bir yere sahip olan konaklama işletmelerinin finansal performanslarının analiz edilmesi önem arz etmektedir. Finansal performans analizinde sıkça kullanılan rasyo (oran) yönteminin turizm işletmelerinin finansal performans göstergelerinin analiz edilmesinde önemli bir araç olduğunu ifade etmek mümkündür.

Turizm işletmeleri, birden fazla alt sektörde faaliyet göstermektedir. Bu işletmeler arasında yer alan konaklama işletmeleri ise otel, hostel, motel, tatil köyleri, pansiyon ve apart otel vb. konaklama hizmeti sunan işletmelerden oluşmaktadır.

Rasyo yöntemi, tıpkı diğer işletmelerde olduğu gibi hizmet sektörünün oldukça dinamik bir alt sektörü olan turizm sektöründe faaliyette bulunan konaklama işletmelerinin likidite, mali yapı, faaliyet durumu ve kârlılık açısından performanslarının ölçülmesinde kullanılan bir analiz yöntemidir.

$\mathrm{Bu}$ çalışmanın amacı, turizm sektöründe faaliyet gösteren turizm işletmelerinden konaklama işletmelerinin (otel vb.) finansal performanslarının rasyo yöntemiyle analiz edilmesidir. Bu amaçla, Türkiye Cumhuriyet Merkez Bankası resmi internet sitesinde yayımlanan sektör bilançoları temin edilerek rasyo yöntemiyle finansal performans analizi gerçekleştirilmiştir.

\section{Literatür Taraması}

Literatürdeki çalışmalar incelendiğinde, turizm işletmelerinin finansal performans analizine yönelik sınırlı bir çalışmanın bulunduğu görülmektedir. Bu çalışmaların sadece birkaçında konaklama işletmelerinde finansal performans analizi üzerinde durulmuştur.

Turizm işletmelerinde finansal performansın analizini konu alan literatürde (ulaşılabilen) yer alan ulusal ve uluslararası düzeydeki çalışmaları aşağıdaki gibi sıralamak mümkündür.

Süslü, Öztürk ve Gök (2019) çalışmalarında; Borsa İstanbul Turizm Endeksi’nde işlem gören işletmelerin 2014-2017 yılları arasındaki finansal performansları rasyo 
Turizm Isşletmelerinde Rasyo Yöntemi ile Finansal Performans Analizi: Konaklama İsletmeleri Üzerine Bir Değerlendirme

yöntemiyle analiz edilmiştir. Çalışma sonucunda, işletmelerin genel olarak finansal yükümlülüklerini yerine getirmede güçlükle karşılaşabilecekleri, bazı işletmelerin varlık ve kaynaklarını etkin bir şekilde kullanamadıkları tespit edilmiştir.

Bilici (2019) çalışmasında; Türkiye Cumhuriyet Merkez Bankası'ndan temin edilen turizm sektöründeki işletmelerin 1996-2016 yıllarına ilişkin bilanço ve gelir tabloları aracılığıyla finansal performanslarının tespiti amacıyla oran analizi ve "Topsis" yöntemi ile analizi gerçekleştirilmiştir. Çalışma sonucunda, turizm sektörünün likidite ve finansal yapı oranları açısından iyi durumda olduğu, aktivite ve kârlılık oranları açısından olumlu sonuçlar elde edilemediği tespit edilmiştir.

Paça ve Tekel Karabulut (2019) çalışmalarında; Borsa İstanbul Turizm Endeksi'nde yer alan işletmelerin finansal performanslarının tespiti amacıyla oran analizi gerçekleştirmişlerdir. Ayrıca, analizde korelasyon testi ve Kruskal Wallis H testi de kullanılmıştır. Çalışma sonucunda, birbirleri ile ilişki dereceleri farklılaşan oranlar ve firmalar arasında aktif devir hızı, çalışma sermayesi devir hızı, net kârın varlık toplamına oranı ile faiz ve vergi öncesi kârın varlık toplamına oranlarında önemli farklılıkların olmadığ 1 tespit edilmiştir.

Karadeniz, Dalak, Günay ve Beyazgül (2019) çalışmalarında; Borsa İstanbul'da işlem gören 12 Türk konaklama işletmesi ile "Brand Finance 2017" sıralamasına göre dünyada marka değeri en yüksek olan ilk 10 yabancı konaklama işletmesinin yatırılan sermayenin getirisi ölçütü (YSG) ile finansal performans analizi gerçekleştirilmiştir. Çalışma sonucunda, "Brand Finance" sıralamasında yer alan yabancı konaklama işletmelerinde en yüksek YSG değerinin 2014 y1lında B1 işletmesinde 23,54 olarak; en düşük YSG değerinin ise 2015 yılında yine B1 işletmesinde -1,07 olarak gerçekleştiği tespit edilmiştir. Borsa İstanbul'da işlem gören Türk işletmelerinde ise, en yüksek YSG değerinin 2012 yılında A10 işletmesinde 3,02 olarak; en düşük YSG değerinin ise 2016 yılında A5 işletmesinde -1,06 olarak gerçekleştiği tespit edilmiştir.

Arslan (2018) çalışmasında; Turizm işletmelerinde kâr marjının belirleyicilerinin araştırılması için oran analizi gerçekleştirilmiştir. Çalışma sonucunda, cari oranın ve aktif büyüklüğünün örneklemdeki işletmeler için kâr marjını pozitif, finansal kaldıraç oranının ve çalışan sayılarının ise kâr marjını negatif yönde etkilediği tespit edilmiştir.

Durmaz (2017) çalışmasında; Hisseleri Borsa İstanbul'da işlem gören turizm işletmelerinin finansal performanslarının hangi unsurlardan etkilendiğinin belirlenmesi amacıyla panel veri regresyon modeli ile analiz gerçekleştirilmiştir. Çalışma sonucunda, turizm işletmelerinin aktif kârlılık oranının, sermaye çarpanı ve aktif devir hızı oranından pozitif yönde, kısa vadeli yabancı kaynaklar ve kaldıraç oranından negatif yönde etkilendiği; faaliyet kârlılık oranının, aktif devir hızı oranından ve net işletme sermayesi devir hızı oranından pozitif yönde, kaldıraç oranından ve ticari alacak devir hızı oranından negatif yönde etkilendiği tespit edilmiştir.

Asdullah ve Rehman (2015) çalışmalarında; Pakistan otel sektöründeki iki büyük isim olan Serena Hotel ve Marriott Hotel'in 2011 ve 2012 yıllarına ilişkin finansal performanslarının analiz edilmesi için oran analizi gerçekleştirilmiştir. Çalışma sonucunda, her iki otelin de 2012 yılında bir önceki yıla göre daha iyi bir performans 
gösterdiği belirtilmiş ve Serena Hotel'in kâr marjının Marriott Hotel'e göre daha yüksek olduğu tespit edilmiştir.

Aznar Alarcón ve Sayeras Maspera (2015) çalışmalarında; İspanya'nın üç ana kıyı bölgesinde faaliyet gösteren otellerin performansındaki farklılıkların belirlenmesi amacıyla oran analizi gerçekleştirilmiştir. Çalışma sonucunda, Costa del Sol otellerinin daha yüksek borç oranlarına sahip olduğu ve bu yüksek oranların faiz oranlarında bir risk primine yol açtı̆̆ tespit edilmiştir.

Borovčanin (2015) çalışmasında; Dört şehir oteli (Holiday Inn Belgrade, Falkensteiner Belgrade, Hotel Zira ve IN Hotel) arasındaki finansal sonuçların karşılaştırılması amacıyla oran analizi gerçekleştirilmiş̧ir. Çalışma sonucunda, karşılaştırma yapılan oteller arasında Falkensteiner Belgrade ve Hotel Zira'nın diğer iki otele göre daha düşük aktivite ve verimliliğge sahip olduğu tespit edilmiştir.

Özçelik ve Kandemir (2015) çalışmalarında; Turizm şirketlerinin finansal performanslarının tespiti amacıyla "Topsis" yöntemi ile analizi gerçekleştirilmiş̧ir. Çalışma sonucunda, en iyi performans sergileyen ilk üç işletmenin 2010 yllında TEKTU, METUR ve AYCES olduğu; 2011 yllında TEKTU, MAALT ve METUR olduğu; 2012 yllında MAALT, METUR ve TEKTU olduğu, 2013 yilında MAALT, METUR ve PKENT olduğu, 2014 yılında ise MAALT, PKENT ve METUR olduğu tespit edilmiştir.

Yusubov (2015) çalışmasında; Borsa İstanbul Turizm Endeksi'nde yer alan işletmelerin finansal performanslarının tespiti amacıyla trend analizi, dikey analiz ve rasyo yöntemleri ile analizi gerçekleştirilmiştir. Çalışma sonucunda, işletmelerin varlık ve kaynak yapılarında genel olarak dengesizlik bulunduğu, varlıkların finansmanında genellikle özkaynaklardan yararlanan işletmelerin likidite sorunlarıyla karşıllaştıkları, bu işletmelerin yıllar itibariyle kısa vadeli borçlarının artış gösterdiği tespit edilmiştir.

Nunes ve Machado (2012) çalışmalarında; Otel işletmelerinde finansal performans ölçümü amacıyla oran analizi gerçekleştirilmiştir. Çalışma sonucunda, otel endüstrisindeki performans değerlendirmelerinde finansal önlemlerin çok fazla ağırlı̆g 1 olduğu tespit edilmiş̧ir.

\section{Konaklama İșletmelerinde Rasyo Yöntemi İle Finansal Performans Analizi}

Bu bölümde, konaklama işletmelerinin finansal performanslarının likidite, mali yapı, faaliyet ve kârllılı durumlarının değerlendirilerek finansal performanslarının analizi gerçekleştirilmiştir.

\section{A. Çalıșmanın Amacı ve Kapsamı}

Çalışmanın amacı, finansal analiz yöntemleri arasında yer alan ve diğer işletmelerde olduğu gibi konaklama işletmelerinde de finansal performansın ölçümünde sıklıkla yararlanılan rasyo analizi yöntemiyle konaklama işletmelerinin finansal performansının analiz edilmesidir. Çalışmanın kapsamını, Türkiye Cumhuriyet Merkez Bankası tarafindan yayımlanan "Konaklama ve Yiyecek Hizmeti Faaliyetleri" başlıklı grupta yer alan otel vb. konaklama işletmelerinin 2015-2019 yılları arasına ait bilanço ve gelir tabloları oluşturmaktadır. 
Turizm Isşletmelerinde Rasyo Yöntemi ile Finansal Performans Analizi: Konaklama İsletmeleri Üzerine Bir Değerlendirme

\section{B. Çalışmanın Yöntemi}

Calışmanın amacı ve kapsamı doğrultusunda konaklama işletmelerine ilișkin temin edilen bilanço ve gelir tablosu verileri dikkate alınarak rasyo yöntemiyle finansal performans analizi gerçekleştirilmiş̧ir.

Konaklama işletmelerinde finansal performansın analizinde kullanılabilecek oranlar ve hesaplanma şekilleri Tablo 1'deki gibidir.

Tablo 1: Oranlar ve Hesaplanma Şekilleri

\begin{tabular}{|c|c|c|}
\hline ORANLAR & $\begin{array}{c}\text { STANDA } \\
\text { RT ORAN }\end{array}$ & HESAPLANMA ŞEKLI \\
\hline \multicolumn{3}{|c|}{ LiKidiTE ORANLARI } \\
\hline Cari Oran & $1,5-2$ & Dönen Varlıklar / Kısa Vadeli Yabancı Kaynaklar \\
\hline Asit Test Oranı & 1 & (Dönen Varlıklar - Stoklar) / Kısa Vadeli Yabancı \\
Kaynaklar
\end{tabular}




\begin{tabular}{|c|c|c|}
\hline \multicolumn{2}{|c|}{ KÂRLILIK ORANLARI } \\
\hline Brüt Satış Kârı Oranı & - & Brüt Satış Kârı / Net Satışlar \\
\hline Faaliyet Kârı Oranı & - & Faaliyet Kârı / Net Satışlar \\
\hline Dönem Net Kârı Oranı & - & Dönem Net Kârı / Net Satışlar \\
\hline Aktif Kârlılık Oranı & - & Dönem Net Kârı / Aktif Toplamı \\
\hline
\end{tabular}

Kaynak: (Çabuk vd., 2019: 64-74'den derlenerek hazırlanmıştır.)

\section{C. Çalışmanın Bulguları}

$\mathrm{Bu}$ çalı̧̧mada, konaklama işletmelerinin likidite, mali yapı, faaliyet ve kârlılık oranları hesaplanarak, finansal performansları değerlendirilmiştir. Türkiye Cumhuriyet Merkez Bankası tarafindan yayımlanan "Konaklama ve Yiyecek Hizmeti Faaliyetleri" başlıklı grupta yer alan otel vb. konaklama işletmelerine ilişkin yapısal analiz ile oran analizine ilişkin bulgular aşağıda yer almaktadır.

Konaklama işletmelerinin yapısal analizine (bilanço analizi) ilişkin bulgular Tablo 2'deki gibidir.

Tablo 2: Konaklama İşletmelerinin Yapısal Analiz Tablosu (Bilanço Analizi)

\begin{tabular}{|c|c|c|c|c|c|}
\hline & 2015 & 2016 & 2017 & 2018 & 2019 \\
\hline \multicolumn{6}{|l|}{ AKTİF YAPISI } \\
\hline Dönen Varlıklar & 27,6 & 26,0 & 27,8 & 30,1 & 31,3 \\
\hline Duran Varlıklar & 72,4 & 74,0 & 72,2 & 69,9 & 68,7 \\
\hline \multicolumn{6}{|l|}{ PASIF YAPISI } \\
\hline Kisa Vadeli Yabancı Kaynaklar & 28,1 & 29,5 & 30,9 & 32,6 & 35,3 \\
\hline Uzun Vadeli Yabancı Kaynaklar & 41,0 & 46,3 & 48,2 & 52,1 & 46,8 \\
\hline Özkaynaklar & 30,9 & 24,2 & 20,8 & 15,3 & 17,9 \\
\hline
\end{tabular}

Kaynak: (Merkez Bankası, agis, 2021) 
Turizm Isşletmelerinde Rasyo Yöntemi ile Finansal Performans Analizi: Konaklama İsletmeleri Üzerine Bir Değerlendirme

Tablo 2'den anlaşılacağı üzere, konaklama işletmelerinin aktif yapısı genel olarak duran varlık ağırlıklıdır. 2016 yılından itibaren dönen varlık oranının artış eğilimine girdiğini, buna karşılık duran varlık oranının azalış eğilimine girdiğini ifade etmek mümkündür. Konaklama işletmelerinin pasif yapısı ise genel olarak uzun vadeli yabancı kaynak ağırlıklıdır. Ancak, 2015 yılından itibaren kısa vadeli yabancı kaynak oranı artış eğilimine girerken, uzun vadeli yabancı kaynak oranının dalgalı bir eğilim gösterdiğini ifade etmek mümkündür. Bununla birlikte, özkaynak oranının da 2015 yılından itibaren sürekli bir azalış eğilimine girdiği gözlemlenmektedir. Tabloya göre, konaklama işletmelerinin varlıklarının çok büyük bir kısmını ağırlıklı olarak yabancı kaynaklarla finanse ettiğini, küçük bir kısmını ise özkaynaklarla finanse ettiğini ifade etmek mümkündür.

Konaklama işletmelerinin yıllar itibariyle likidite oranlarına ilişkin bulgular Tablo 3 'teki gibidir.

Tablo 3: Yıllar İtibariyle Likidite Oranlarına İlişkin Bulgular

\begin{tabular}{|c|r|r|r|r|r|}
\hline ORANLAR & $\mathbf{2 0 1 5}$ & $\mathbf{2 0 1 6}$ & $\mathbf{2 0 1 7}$ & $\mathbf{2 0 1 8}$ & $\mathbf{2 0 1 9}$ \\
\hline Cari Oran & 0,98 & 0,88 & 0,89 & 0,92 & 0,89 \\
\hline Asit Test Oranı & 0,79 & 0,69 & 0,72 & 0,73 & 0,70 \\
\hline Nakit Oranı & 0,27 & 0,18 & 0,20 & 0,23 & 0,23 \\
\hline
\end{tabular}

Likidite oranları, işletmelerin kısa vadeli borç ödeme güçlerini gösteren oranlardır. Tablo 3'e göre, konaklama işletmelerinin 2015-2019 yılları arasındaki cari oranları birbirine yakın ve dalgalı bir eğilim göstermektedir. İşletmelerin dönen varlıkları ile kısa vadeli borç ödeme gücünü gösteren cari oranın standart oranı 2 olmakla birlikte, bu oranın gelişmekte olan ülkelerde 1,5 olması yeterli görülmektedir. Elde edilen bulgulara göre, konaklama işletmelerinde bu oranın standart orana göre oldukça düşük olduğu görülmektedir. Bu durum, konaklama işletmelerinin dönen varlıkları ile kısa vadeli borç ödeme güçlerinin yeterli olmadığını ortaya koymaktadır. Konaklama işletmelerinin 2015-2019 yılları arasındaki asit test oranlarının 2015 yılından sonra 2018 yılı hariç düşüş eğiliminde olduğu görülmektedir. İşletmelerin stoklar hariç likiditesi yüksek dönen varlıkları ile kısa vadeli borç ödeme gücünü gösteren asit test oranının standart oranı 1'dir. Elde edilen bulgulara göre, konaklama işletmelerinde bu oran standart orandan biraz düşük olmakla birlikte, kısa vadeli borçların ödenmesi noktasında güçlük çektikleri şeklinde yorumlanabilir. Konaklama işletmelerinin 2015-2019 yılları arasındaki nakit oranlarının 2015 yılı hariç birbirine yakın bir eğilim gösterdiği görülmektedir. İşletmelerin stoklarını elden çıkaramaması ve alacaklarını tahsil edememesi durumunda dahi elindeki nakit ve nakit benzerleri varlıkları ile kısa vadeli borç ödeme gücünü gösteren nakit oranının standardı 0,20'dir. Elde edilen bulgulara göre, konaklama işletmelerinde bu oran 2016 yılı hariç standart oranın üzerindedir. Buna göre, konaklama işletmelerinin 2016 yılı hariç hazır değerleri (kasa, banka vb.) ile kısa 
vadeli borç ödeme güçlerinin yeterli olduğunu, 2016 yılında ise hazır değerleri ile kısa vadeli borç ödeme noktasında güçlük çektiklerini ifade etmek mümkündür.

Konaklama işletmelerinin yıllar itibariyle mali yapı oranlarına ilişkin bulgular Tablo 4 'teki gibidir.

Tablo 4: Yııllar İtibariyle Mali Yapı Oranlarına İlişkin Bulgular

\begin{tabular}{|c|c|c|c|c|c|}
\hline ORANLAR & $\mathbf{2 0 1 5}$ & $\mathbf{2 0 1 6}$ & $\mathbf{2 0 1 7}$ & $\mathbf{2 0 1 8}$ & $\mathbf{2 0 1 9}$ \\
\hline $\begin{array}{c}\text { Yabancı Kaynak Oranı } \\
\text { (Kaldıraç Oranı) }\end{array}$ & 0,69 & 0,75 & 0,79 & 0,84 & 0,82 \\
\hline Özkaynaklar Oranı & 0,31 & 0,25 & 0,21 & 0,16 & 0,18 \\
\hline $\begin{array}{c}\text { Kisa Vadeli Yabancı } \\
\text { Kaynak Oranı }\end{array}$ & 0,28 & 0,29 & 0,31 & 0,33 & 0,35 \\
\hline $\begin{array}{c}\text { Uzun Vadeli Yabancı } \\
\text { Kaynak Oranı }\end{array}$ & 0,41 & 0,46 & 0,48 & 0,51 & 0,47 \\
\hline
\end{tabular}

Mali yapı oranları, işletmelerin uzun vadeli borç ödeme güçlerini ve kaynak yapısını gösteren oranlardır. Tablo 4'e göre, kaldıraç oranı olarak da adlandırılan yabancı kaynak oranı 2015-2018 yılları arasında artan bir eğilim göstermektedir. Buna karşın, özkaynaklar oranı aynı yıllar arasında azalan bir eğilim göstermektedir. Yabancı kaynak ve özkaynaklar oranının standart oranı 0,50'dir. Ancak, gelişmekte olan ülkelerde bu oranların sırasıyla 0,70 ve 0,30 dolaylarında olması uygun görülmektedir. Tablodan anlaşılacağı üzere, konaklama işletmelerinde 2015 yılı hariç varlıkların finansmanında standart oranların çok üzerinde bir yabancı kaynak kullanımı ile standart oranların çok altında bir özkaynak kullanımının gerçekleștiğini ifade etmek mümkündür. Kaldıraç oranının standart orandan bu denli yüksek olması, konaklama işletmeciliği sektöründe yabancı kaynak ağırlıklı bir finansman stratejisinin izlendiğinin açık göstergesidir. Kısa vadeli yabancı kaynak oranı 2015-2019 yılları arasında artan bir eğilim göstermektedir. Aynı şekilde, uzun vadeli yabancı kaynak oranı da 2019 yılı hariç artan bir eğilim göstermektedir. Bu durum, işletmelerin yabancı kaynak kullanımında uzun vadeli yabancı kaynaklara daha fazla ağırlık verdiği şeklinde yorumlanabilir.

Konaklama işletmelerinin yıllar itibariyle faaliyet oranlarına ilişkin bulgular Tablo 5 'teki gibidir. 
Turizm Isşletmelerinde Rasyo Yöntemi ile Finansal Performans Analizi: Konaklama İsletmeleri Üzerine Bir Değerlendirme

Tablo 5: Yıllar İtibariyle Faaliyet Oranlarına İlişkin Bulgular

\begin{tabular}{|c|c|c|c|c|c|}
\hline ORANLAR & $\mathbf{2 0 1 5}$ & $\mathbf{2 0 1 6}$ & $\mathbf{2 0 1 7}$ & $\mathbf{2 0 1 8}$ & $\mathbf{2 0 1 9}$ \\
\hline Alacak Devir Hızı & 3,88 & 2,80 & 3,24 & 3,95 & 4,12 \\
\hline Alacak Tahsil Süresi & 94 & 130 & 112 & 92 & 88 \\
\hline Stok Devir Hızı & 3,71 & 2,88 & 3,17 & 3,21 & 3,55 \\
\hline Stok Devir Süresi & 98 & 126 & 115 & 113 & 102 \\
\hline Aktif Devir Hızı & 0,27 & 0,18 & 0,24 & 0,34 & 0,36 \\
\hline
\end{tabular}

Faaliyet oranları, işletmelerin varlıklarının ne ölçüde etkin ve verimli kullanıldıklarının tespit edilmesi için kullanılan oranlardır. Tablo 5'e göre, alacakların yılda kaç kez tahsil edildiğini gösteren alacak devir hızının 2,80 ile 4,12 aralığında bir değişim gösterdiği görülmektedir. Alacakların kaç günde tahsil edildiğini gösteren alacak tahsil süresinin ise 92 ile 130 aralığında bir değişim gösterdiği görülmektedir. Bu durum, alacakların yılda ortalama 3-4 kez ve 92-130 günlük aralıklarla tahsil edildiğini göstermektedir. Stokların satışa dönüştürülerek elden çıkarılma hızını gösteren stok devir hızının 2,88 ile 3,71 aralığında bir değişim gösterdiği görülmektedir. Stokların ortalama stoklarda kalma süresini gösteren stok devir süresinin ise 98 ile 126 aralığında bir değişim gösterdiği görülmektedir. Bu durum, stokların yılda ortalama 3-4 kez ve 98126 günlük aralıklarla satışa dönüştürüldügünü göstermektedir. İşletmelerin aktifinde yer alan varlıkların kaç katı satış yapıldığını gösteren aktif devir hızının 2016 yılı hariç artan bir eğilim gösterdiği görülmektedir.

Konaklama işletmelerinin yıllar itibariyle kârlılık oranlarına ilişkin bulgular Tablo 6'daki gibidir.

Tablo 6: Yıllar İtibariyle Kârlılık Oranlarına İlişkin Bulgular

\begin{tabular}{|c|c|c|c|c|c|}
\hline ORANLAR & $\mathbf{2 0 1 5}$ & $\mathbf{2 0 1 6}$ & $\mathbf{2 0 1 7}$ & $\mathbf{2 0 1 8}$ & $\mathbf{2 0 1 9}$ \\
\hline Brüt Satıs Kârı Oranı & 0,29 & 0,19 & 0,29 & 0,41 & 0,37 \\
\hline Faaliyet Kârı Oranı & 0,06 & $-0,10$ & 0,07 & 0,22 & 0,19 \\
\hline $\begin{array}{c}\text { Dönem Net Kârı } \\
\text { Oranı }\end{array}$ & $-0,06$ & $-0,33$ & $-0,17$ & $-0,10$ & 0,05 \\
\hline \begin{tabular}{c} 
Aktif Kârıııı Oranı \\
\hline
\end{tabular} & $-0,02$ & $-0,06$ & $-0,04$ & $-0,03$ & 0,02 \\
\hline
\end{tabular}


Kârlılık oranları, işletmelerin gerek esas faaliyetleri gerekse diğer faaliyetleri sonucu ne ölçüde başarılı, verimli ve etkin şekilde yönetildiğinin tespit edilmesi için kullanılan oranlardır. Tablo 6'ya göre, işletmelerin brüt satışları sonucu kâr marjını yansıtan brüt satış kârı oranı yıllar itibariyle dalgalı bir seyir izlemekle birlikte özellikle 2018 ve 2019 yıllarında diğer yıllara göre artış eğilimi göstermektedir. İşletmelerin esas faaliyetleri sonucu kâr marjını yansıtan faaliyet kârı oranı 2016 yılı hariç 0,06 ile 0,22 arasında değişiklik göstermektedir. 2016 yılında ise faaliyet zararı ortaya çıktı̆ıını ifade etmek mümkündür. İşletmelerin dönem net kârının satışlar içerisindeki oranını yansıtan dönem net kârı oranı yıllar itibariyle 2019 yılı hariç negatif bir eğilim göstermektedir. Bu durum, işletmelerin 2019 yılı hariç dönemi net zararla kapattıklarının göstergesidir. Aktif varlıkların ne ölçüde etkin ve verimli kullanıldığını yansıtan aktif kârlılık oranı da dönem net kârı oranına paralel şekilde 2019 yılı hariç negatif bir eğilim göstermektedir. Karlılık oranları dikkate alındığında, konaklama işletmelerinin 2019 yılı haricinde iyi bir performans göstermediklerini ifade etmek mümkündür.

\section{Sonuç, Değerlendirme ve Öneriler}

Turizm sektörü, ülke ekonomileri için çok önemli bir sektördür. Özellikle, önemli düzeyde döviz girdisi sağlaması ve istihdam yaratması bakımından önemli bir rol üstlenmektedir. Turizm sektörü, büyük bir alana yayılan ve çok sayıda alt sektörde faaliyette bulunan işletmelerden oluşmaktadır.

Turizm sektörü içerisinde en büyük payın konaklama işletmelerine ait olduğunu ifade etmek mümkündür. Günümüzde yaşanan rekabetle birlikte hızla gelişim kaydeden ve dinamik bir yapısı bulunan konaklama işletmelerinin finansal açıdan etkinlik ve verimliliklerinin analiz edilmesi son derece önem arz etmektedir. Bu öneme binaen, Türkiye Cumhuriyet Merkez Bankası tarafindan yayımlanan "Konaklama ve Yiyecek Hizmeti Faaliyetleri" başlıklı grupta yer alan otel vb. konaklama işletmelerinin 20152019 yılları arasına ait bilanço ve gelir tabloları temin edilmiş ve rasyo yöntemiyle finansal analizi gerçekleştirilmiştir. Finansal analiz neticesinde elde edilen bulgular ışığında aşağıdaki değerlendirmeleri yapmak mümkündür.

Konaklama işletmelerine ait likidite oranları değerlendirildiğinde; özellikle cari oran ve asit test oranının sektörde standart olarak kabul edilen oranların oldukça altında olduğu tespit edilmiştir. Bu durum, konaklama işletmelerinin kısa vadeli borçlarını ödeme noktasında güçlük çektiklerinin göstergesidir. Bu noktada, konaklama işletmeleri tarafindan bu iki oranın daha iyi duruma getirilmesi için alacakların tahsil sürelerinin kısaltılması, kısa vadeli borçların vadelerinin uzatılması, atıl durumdaki duran varlıkların elden çıkarılması gibi girişimlerde bulunulması önerilebilir.

Konaklama işletmelerine ait mali yapı oranları değerlendirildiğinde; yabancı kaynak oranı ve özkaynaklar oranının sektörde standart olarak kabul edilen oranlardan oldukça farklılaştığ 1 tespit edilmiştir. Buna göre, konaklama işletmelerinin varlıkların finansmanında çok büyük oranda yabancı kaynaklara ağırlık verdikleri belirlenmiştir. Bununla birlikte, yabancı kaynak kullanımında da ağırlığın uzun vadeli yabancı kaynaklarda olduğu tespit edilmiştir. Bu noktada, konaklama işletmeleri tarafından yabancı kaynak/özkaynaklar dengesinin iyi kurulması ve yabancı kaynak kullanımına 
Turizm Isşletmelerinde Rasyo Yöntemi ile Finansal Performans Analizi: Konaklama İsletmeleri Üzerine Bir Değerlendirme

bağlı borçlanma maliyetlerinin olumsuz etkilerinden korunabilmelerini sağlayacak girişimlerde bulunulması önerilebilir.

Konaklama işletmelerine ait faaliyet oranları değerlendirildiğinde; alacak devir hızının 2,80 ile 4,12 aralığında bir değişim gösterdiği, alacak tahsil süresinin ise 92 ile 130 aralığında bir değişim gösterdiği tespit edilmiştir. Bu durum, alacakların yılda ortalama 3-4 kez ve 92-130 günlük aralıklarla tahsil edildiğinin göstergesidir. Ayrıca, stok devir hızının 2,88 ile 3,71 aralığında bir değişim gösterdiği, stok devir süresinin ise 98 ile 126 aralığında bir değişim gösterdiği tespit edilmiştir. Bu durum da, stokların yılda ortalama 3-4 kez ve 98-126 günlük aralıklarla satışa dönüştürüldügünün göstergesidir. $\mathrm{Bu}$ noktada, konaklama işletmeleri tarafından faaliyet oranlarının iyileştirilmesi amacıyla alacak tahsil sürelerinin ve stokların elden çıkarılma sürelerinin kısaltılması amacıyla etkin bir alacak-satış-tahsilat politikasının izlenmesine yönelik girişimlerde bulunulması önerilebilir.

Konaklama işletmelerine ait kârlılık oranları değerlendirildiğinde; brüt satış kârı oranı ve faaliyet kârı oranının 2016 yılı hariç diğer yıllarda genel olarak artan bir eğilim gösterdiği, dönem net kârı oranı ve aktif kârlılık oranının 2019 yılı hariç diğer yıllarda negatif bir eğilim gösterdiğgi tespit edilmiştir. Bu durum, konaklama işletmeciliği sektöründe 2015-2018 yılları arasında zarar meydana geldiğinin göstergesidir. Bu noktada, konaklama işletmeleri tarafindan esas faaliyetler dışında ortaya çıkan yüksek tutardaki diğer faaliyetlerden olağan gider ve zarar tutarı ile finansman giderlerinin düşürülmesine yönelik girişimlerde bulunulması önerilebilir.

Çalışma kapsamında elde edilen bulgular ışı̆̆ında yapılan değerlendirmelerin dikkate alınması ile konaklama işletmelerinin finansal yapılarının güçlenebileceğini ve böylece finansal analiz sonucunda elde edilen oranların iyileştirilerek sektördeki standart oranları yakalayabileceğini ifade etmek mümkündür.

\section{Kaynaklar}

Arslan, S. (2018). Kâr Marjının belirleyicilerinin İncelenmesi: Turizm İşletmeleri Üzerine Bir Uygulama. Turkish Studies-Econamics, Finance and Politics, 13(30): 51-62.

Asdullah, M. A. and Rehman, Z. U. (2015). A Comparative Study on Financial Performance of Hotel Industry in Pakistan: (Sarena Hotel \& Marriott Hotel). Journal of Tourism, Hospitality and Sports, 8, 42-54.

Aznar Alarcón, J. P. and Sayeras Maspera, J. M. (2015). The Financial and Economic Performance of Hotels in Spanish Beach Tourist Destinations. Athens Journal of Tourism, 2(3): 141-152.

Bilici, N. (2019). Turizm Sektörünün Finansal Performansının Oran Analizi ve Topsis Yöntemiyle Değerlendirilmesi. Atatürk Üniversitesi Sosyal Bilimler Enstitüsü Dergisi, 23(1): 173-194.

Borovčanin, D. (2015). A Comparative Analysis on Hotel Financial Performance. Erişim Adresi: 
https://www.researchgate.net/publication/290315731_A_COMPARATIVE_ANAL YSIS_ON_HOTEL_FINANCIAL_PERFORMANCE. Erişim Tarihi: 13.06.2021.

Çabuk, A., Karagül, A. A., Erol, C., Başar, A. B., Sevim, Ş. ve Sayılır, Ö. (2019). Finansal Tablolar Analizi. Anadolu Üniversitesi Yayınları.

Durmaz, M. (2017). Borsa İstanbul'da İşlem Gören Konaklama İşletmelerinde Finansal Performansı Belirleyen Faktörler: Panel Veri Analizi. Yayımlanmamış Yüksek Lisans Tezi. Akdeniz Üniversitesi Sosyal Bilimler Enstitüsü.

Karadeniz, E., Dalak, S., Günay, F. ve Beyazgül, M. (2019). Konaklama İşletmelerinde Finansal Performans Ölçütü Olarak Yatırılan Sermayenin Getirisi. Anatolia: Turizm Araştırmaları Dergisi, 30(1): 31-44.

Merkez Bankası (2021). Sektör Bilançoları. Erişim Adresi: http://www3.tcmb.gov.tr/sektor/2020/\#/tr, Erişim Tarihi: 12.06.2021.

Nunes, C. R. and Machado, M. J. C. V. (2012). Financial Assessment of Performance in the Hotel Industry. European Journal of Tourism, Hospitality and Recreation, 3 (Special Issue): 97-109.

Özçelik, H. ve Kandemir, B. (2015). BİST'de İşlem Gören Turizm İşletmelerinin Topsis Yöntemi İle Finansal Performanslarının Değerlendirilmesi. Balıkesir Üniversitesi Sosyal Bilimler Enstitüsü Dergisi, 18(33): 97-114.

Paça, M. ve Tekel Karabulut, M. (2019). Finansal Rasyolar İle Finansal Performans: Bist ve Turizm. Uluslararası Global Turizm Araştırmaları Dergisi, 3(1): 53-65.

Süslü, C., Öztürk, F. B. ve Gök, M. A. (2019, 19-20 Nisan). Türkiye’de Turizm Şirketlerinin Finansal Performansinın Incelenmesi. VIII. Ulusal IV. Uluslararası Doğu Akdeniz Turizm Sempozyumu, Mersin.

Yusubov, F. (2015). Turizm İşletmelerinde Finansal Analiz ve Performans Değerlendirmesi (Borsa İstanbul Üzerinde Araştırma). Yayımlanmamış Yüksek Lisans Tezi, Sakarya Üniversitesi Sosyal Bilimler Enstitüsü. 